\title{
Process evaluation of a multi-component self- management intervention for adults with epilepsy (ZMILE study)
}

Citation for published version (APA):

Leenen, L. A. M., Wijnen, B. F. M., van Haastregt, J. C. M., de Kinderen, R. J. A., Evers, S. M. A. A., Majoie, M. H. J. M., \& van Heugten, C. M. (2017). Process evaluation of a multi-component selfmanagement intervention for adults with epilepsy (ZMILE study). Epilepsy \& Behavior, 73, 64-70. https://doi.org/10.1016/j.yebeh.2017.05.023

Document status and date:

Published: 01/08/2017

DOI:

10.1016/j.yebeh.2017.05.023

Document Version:

Publisher's PDF, also known as Version of record

Document license:

Taverne

Please check the document version of this publication:

- A submitted manuscript is the version of the article upon submission and before peer-review. There can be important differences between the submitted version and the official published version of record.

People interested in the research are advised to contact the author for the final version of the publication, or visit the DOI to the publisher's website.

- The final author version and the galley proof are versions of the publication after peer review.

- The final published version features the final layout of the paper including the volume, issue and page numbers.

Link to publication

\footnotetext{
General rights rights.

- You may freely distribute the URL identifying the publication in the public portal. please follow below link for the End User Agreement:

www.umlib.nl/taverne-license

Take down policy

If you believe that this document breaches copyright please contact us at:

repository@maastrichtuniversity.nl

providing details and we will investigate your claim.
}

Copyright and moral rights for the publications made accessible in the public portal are retained by the authors and/or other copyright owners and it is a condition of accessing publications that users recognise and abide by the legal requirements associated with these

- Users may download and print one copy of any publication from the public portal for the purpose of private study or research.

- You may not further distribute the material or use it for any profit-making activity or commercial gain

If the publication is distributed under the terms of Article $25 \mathrm{fa}$ of the Dutch Copyright Act, indicated by the "Taverne" license above, 


\title{
Process evaluation of a multi-component self-management intervention for adults with epilepsy (ZMILE study)
}

\author{
Loes A.M. Leenen ${ }^{\text {a,b,c,* }}$, Ben F.M. Wijnen ${ }^{\text {a,b }}$, Jolanda C.M. van Haastregt ${ }^{a}$, Reina J.A. de Kinderen ${ }^{g}$, \\ Silvia M.A.A. Evers ${ }^{\mathrm{a}, \mathrm{g}}$, Marian H.J.M. Majoie ${ }^{\mathrm{b}, \mathrm{c}, \mathrm{d}, \mathrm{e}}$, Caroline M. van Heugten ${ }^{\mathrm{d}, \mathrm{f}}$
}

${ }^{a}$ Faculty of Health, Medicine and Life Sciences, Department of Health Services Research, CAPHRI Care and Public Health Institute, Maastricht University, Maastricht, The Netherlands

${ }^{\mathrm{b}}$ Department of Research \& Development, Academic Centre of Epileptology Kempenhaeghe Maastricht UMC + , The Netherlands

${ }^{c}$ Department of Neurology, Academic Centre of Epileptology Kempenhaeghe Maastricht UMC + , The Netherlands

d School for Mental Health and Neuroscience (MHENS), Maastricht University Medical Centre, Maastricht, The Netherlands

e School of Health Professions Education, Faculty of Health, Medicine and Life Sciences, Maastricht University, Maastricht, The Netherlands

${ }^{\mathrm{f}}$ Faculty of Psychology and Neurosciences: Department of Neuropsychology and Psychopharmacology, Maastricht University, Maastricht, The Netherlands

g Trimbos Institute, Netherlands Institute of Mental Health and Addiction, Utrecht, The Netherlands

\section{A R T I C L E I N F O}

\section{Article history:}

Received 29 March 2017

Revised 16 May 2017

Accepted 16 May 2017

Available online 15 June 2017

\section{Keywords:}

Self-management intervention

eHealth

Pro-active goal-setting

Peer support

Social support

Shared decision-making

\begin{abstract}
A B S T R A C T
Background: People with epilepsy need to monitor and manage their symptoms. They, as well as their relatives, have to deal with the psychological burden, reflected in a reduced quality of life. Support in self-management can be of importance. We have developed a multi-component self-management intervention for patients and their relatives (MCI). This eight-week group intervention is conducted by nurse practitioners and consists of six two-hour sessions. The main components are: 1) providing self-management education, 2) stimulating proactive coping and goal-setting and 3) facilitating peer and social support.

This study is a process evaluation to establish the feasibility, fidelity and acceptability of the intervention by assessing performance according to protocol, attendance and adherence, and the opinion of patients, relatives and facilitators about the intervention.

Method: Study population consists of 52 patients with epilepsy living in the community (e.g. at home), 37 relatives and six facilitators. In this prospective mixed methods study, data were gathered using questionnaires for patients and relatives, registration forms for facilitators and by carrying out semi-structured group interviews with patients, relatives and facilitators.

Results: Patients and relatives attended a mean of 5.2 sessions. Forty-seven (90\%) patients and 32 (86.5\%) relatives attended at least five sessions. The mean group size was 8.1 ( $S D=1.3$; range $6-10)$. All elements of the intervention were offered to participants, except for one e-Health tool which was only available at the start of the study. Overall, the sessions were considered useful by patients, their relatives and facilitators. The participation of a relative (social support) and sharing ideas and feelings about having epilepsy with peers (peer support) were rated as important aspects.

Conclusion: This process evaluation revealed that the MCI was largely performed according to protocol, attendance rate was high, and participants and facilitators had, on the whole, a favourable opinion about the $\mathrm{MCI}$, and would recommend it to others with epilepsy and their relatives. Overall, the adherence of patients and relatives was high. The $\mathrm{MCI}$ is considered feasible according to patients, relatives and facilitators. Implementation is recommended if the intervention proves to be effective.
\end{abstract}

(C) 2017 Elsevier Inc. All rights reserved.

\footnotetext{
* Corresponding author at: Sterkselseweg 65, P.O. Box Heeze, The Netherlands.

E-mail addresses: leenenl@kempenhaeghe.nl (L.A.M. Leenen), b.wijnen@maastrichtuniversity.nl (B.F.M. Wijnen),

j.vanhaastregt@maastrichtuniversity.nl (J.C.M. van Haastregt), RKinderen@trimbos.nl (R.J.A. de Kinderen), s.evers@maastrichtuniversity.nl (S.M.A.A. Evers), majoiem@kempenhaeghe.nl (M.H.J.M. Majoie), c.vanheugten@maastrichtuniversity.nl (C.M. van Heugten).
}

\section{Introduction}

Epilepsy has considerable effects on the everyday lives of people with epilepsy and their relatives. The seizures, which are the result of sudden electrical discharges in groups of brain cells, manifest clinically in a variety of ways, depending on the area in the brain where the discharges occur [1]. The psychological burden of having epilepsy is substantial, and is reflected in a reduced quality of life [2,3]. Furthermore, 
the societal costs are considerable [4,5]. Unemployment rates, for instance, are twice as high among people with epilepsy compared to the general population [6,7]. One way to control health care costs is to stimulate self-management and the use of eHealth $[8,9]$.

People with a chronic condition, such as epilepsy, need to manage their symptoms, by acquiring disease-specific knowledge, adhering to treatment and lifestyle regimens, and coping with the psychosocial consequences of having a chronic condition [10-12].

In order to change health behaviour, knowledge and skills are required but one should also focus on self-management education. Here, the emphasis is placed on how patients and relatives can be actively involved in the treatment plan and how skills can be integrated into their everyday lives, e.g. by performing self-monitoring. According to Faber [13], self-management education should be accompanied by peer support, goal-setting skills, involvement of patients in their treatment plan and self-monitoring. Furthermore, there should be collaborative decision-making, leading to a consensus about the treatment plan (i.e. concordance) [14]. These factors are associated with self-efficacy, defined as the confidence a person has to perform tasks to attain a desired goal $[13,15]$.

Bradley and colleagues [16] performed a systematic review to assess the effectiveness of self-management interventions for adults with epilepsy. The main focus of the included studies was either to improve knowledge about epilepsy or to provide strategies to improve compliance. As explained above, however, this is not sufficient to change behaviour.

We have developed a multi-component self-management intervention (MCI) based on the idea that, in order to manage symptoms and physical and psychosocial consequences of epilepsy, patients must also be taught about self-monitoring (by means of e-Health tools) and risk management. Also, in order to alter behaviour, there should be an emphasis on proactive coping, shared decision-making, resulting in concordance, and goal-setting [17]. The $\mathrm{MCI}$ is based on a selfmanagement intervention specifically designed for stroke patients [18]. Both interventions had the same structure of group sessions followed by a booster session. Participants were patients with a relative which were both asked to formulate a goal using the framework of a 'proactive action plan' in both interventions. In both interventions theme related information was given and discussed with participants. The themes (topics) were adjusted from stroke to epilepsy in agreement with, among others, representatives of the Epilepsy Association of the Netherlands (EVN, Epilepsie Vereniging Nederland) to make them suitable for people with epilepsy.

There are some minor differences between both interventions; number of group sessions is one less in the $\mathrm{MCI}$. In the $\mathrm{MCl}$ we focussed more on how to use the frame work in formulating goals instead of formulating a goal on every theme, as was done in the stroke intervention.

The clinical-effectiveness and cost-effectiveness of the $\mathrm{MCI}$ are currently being evaluated in a randomized controlled trial (RCT) [19]. At the same time, a detailed process evaluation has been performed to assess the feasibility of the $\mathrm{MCI}$ and with the aim of analysing the extent to which it was performed according to protocol, the attendance and adherence of patients and their relatives, and the opinion of patients, their relatives and care professionals (i.e. facilitators) about the MCI. The results of this study can be used to optimize the intervention, to facilitate a correct interpretation of the results of the effect evaluation, and eventually facilitate implementation in the regular care of patients with epilepsy.

\section{Methods}

The MCI was conducted by six facilitators between May 2015 and January 2016, at three locations in the southern part of The Netherlands (Heeze, Nijmegen and Maastricht). Its observational prospective design combines qualitative and quantitative research methods (mixed methods). The process evaluation is conducted according to the framework of Saunders et al. [20], addressing performance as described in the protocol (dose delivered), attendance and adherence (reach, dose received exposure and recruitment), and the patients', relatives' and care professionals' opinion about the $\mathrm{MCI}$ (dose received satisfaction).

\subsection{Multi component intervention}

The intervention focuses on increasing participants' understanding of the medical regimen, thus enhancing skills and providing tools to strengthen self-management and communication between patient, relative and health care professionals, and eventually increasing concordance. The $\mathrm{MCI}$ consists of five weekly group sessions of $2 \mathrm{~h}$ each, followed by a two-hour booster session after three weeks.

The MCI groups are composed of three to six patients and a number of relatives. Each patient can invite one of his/her relatives to participate in the groups. Since not every patient brings a relative, the intended group size varies between 4 and 12 participants. Structure and content of the MCI are shown in Tables 1 and 2.

The sessions consist of two components: education and practicing goal-setting skills. The educational component includes the topics: self-monitoring; risk evaluation; and shared decision-making/ concordance. The aim of this educational part of the sessions was to enhance self-efficacy by discussing and sharing strategies about the topics mentioned above. Two eHealth tools were used for self-monitoring: The Medication Event Monitoring System (MEMS; Aardex Ltd., Switzerland) and the smartphone application 'Eppy' (Epilepsy Foundation, The Netherlands). The MEMS are electronic caps which fit on standard pill bottles and register date and time every time the bottle is opened. The data from the electronic caps can be downloaded and used by the care professional to provide feedback to the patient, in order to improve concordance.

In this process evaluation, MEMS was evaluated as a self-monitor tool that gave patients insight in their pattern of medication intake, by using the electronic gathered data as feedback for patients. Thus, patients were asked to fill the MEMS with either one of their anti-epileptic drugs, or to put the MEMS next to their pill-minder and open the MEMS during their normal routine. Feedback was given by the facilitators during the intervention (sessions 4-6) and by clinicians every 3 months until the end of the follow-up period. Furthermore the LCD screen on top of the cap provides the patient with information whether medication was taken or not.

The Eppy is an application, which can be downloaded to a smartphone or tablet. It enables patients to keep a seizure diary, to set reminders for taking medication and an alarm mode in case of a seizure. Data gathered in this way can be synchronized to a website owned by the patient.

The goal-setting component is based on the five stages of proactive coping defined by Aspinwall \& Taylor [17]: 1) resource accumulation, 2) recognition of potential stressors, 3) initial appraisal, 4) preliminary coping efforts, and 5) elicitation and use of feedback concerning initial efforts. Participants formulate proactive action plans structured according to these five stages [21].

\section{Table 1}

Characteristics of the $\mathrm{MCI}$.

\begin{tabular}{|c|c|}
\hline Participants & People with epilepsy and their relatives \\
\hline \multirow[t]{2}{*}{ Facilitators } & $\begin{array}{l}\text { Nurse practitioners, experienced in working with groups of epilepsy } \\
\text { patients. }\end{array}$ \\
\hline & Two facilitators per group \\
\hline \multirow[t]{3}{*}{ Intervention } & $\begin{array}{l}\text { Duration } \begin{array}{l}\text { Eight weeks, with five weekly sessions of two-hours } \\
\text { and a two-hour booster session in week } 8 \text {. }\end{array}\end{array}$ \\
\hline & $\begin{array}{l}4-6 \text { epilepsy patients with the possibility to bring a } \\
\text { relative. Total: } 4-12 \text { participants }\end{array}$ \\
\hline & $\begin{array}{l}\text { Three locations in the Netherlands (Heeze, Maastricht } \\
\text { and Nijmegen) }\end{array}$ \\
\hline Materials & $\begin{array}{l}\text { A protocol and PowerPoint presentation for the facilitators } \\
\text { eHealth-tools for participants: MEMS and Eppy } \\
\text { A workbook for the participants }\end{array}$ \\
\hline
\end{tabular}


Table 2

Content of the MCI-sessions.

\begin{tabular}{ll}
\hline Session & Topics \\
\hline 1 & Introduction of the MCI \\
& Time for introduction of participants and facilitators \\
& Sharing what it means to have epilepsy or having a relative with epilepsy \\
& Sharing expectations about the MCI \\
& Introduction of the framework of the 'proactive action plan', which is a \\
& 5-step approach for goalsetting. \\
& Participants answering questions which represent the first two steps of \\
& the framework \\
"What do I want to work on?" & "What do I want to achieve?" \\
& Sharing believes, strategies used, emotions and experiences about the topics. \\
& Topic: Self-monitoring \\
Introduction to self-monitoring. Discussing whether participants are & \\
& using self-monitoring tools and what kind of tools are used? \\
Introduction of eHealth-tools (MEMS and 'Eppy'). \\
Participants focus on the third step of the framework on: \\
"What are the barriers, which prevent me from achieving a goal?" and \\
"What are possible solutions for the earlier established barriers?" \\
Sharing believes, strategies used, emotions and experiences about the topics. \\
Topic: Risk- evaluation \\
What are the perceived risks of having epilepsy, according to the \\
participants? How to deal with perceived risks in daily life? \\
Participants focus on the fourth step of the framework on: \\
"What am I actually going to do?" \\
Sharing believes, strategies used, emotions and experiences about the topics. \\
Topic: Communication with a health care provider \\
The need to communicate with a health care provider in order to become \\
involved in one's treatment plan. \\
Participants focus on the last step in the framework which evaluates the \\
previous steps: \\
"How did it go?" \\
Sharing believes, strategies used, emotions and experiences about the topics. \\
Recapitulating the content of the intervention \\
Evaluating and sharing experiences on participants' action plans \\
5 \\
5
\end{tabular}

After a two-hour training by the author (LL) to explain the aim and method, the $\mathrm{MCI}$ is conducted by two facilitators (nurse practitioners). They had also followed a two-day course on motivational interviewing techniques, given by a licenced trainer, in which they were taught to ask the participants questions rather than providing a solution to a problem in order to increase self-management skills. Motivational interviewing is a technique to empower participants to set their own sustainable goals and analyse conflicting beliefs [22,23]. To support the facilitators, throughout the intervention period, there was a weekly interaction with the researcher (LL).

\subsection{Participants}

\subsubsection{Patients}

The process evaluation was conducted among the 52 patients who were allocated to the intervention group of the ZMILE-study (RCT) [19]. The patients, included between March 2014 and December 2015, were recruited in the Academic Centre for Epileptology Kempenhaeghe, The Netherlands, by press releases in national epilepsy magazines (Epilepsie, Transmissie) and via social media (Facebook). Inclusion criteria were: aged 18 years or over, living at home, diagnosed with epilepsy and using anti-epileptic drugs, being able to speak and understand Dutch, willing and able to use eHealth devices like a smartphone, and providing written informed consent. Excluded were patients who, based on clinical judgement, were not able or willing to function in group activities and patients who were not able to comprehend topics discussed in the MCI.

\subsubsection{Relatives}

Thirty-seven of the 52 patients in the intervention group had a relative who agreed to participate in the intervention. Relative was defined as partner, spouse or other family member closely related to the patient. There were no additional in- or exclusion criteria for the group of relatives.

\subsubsection{Facilitators}

Five nurse practitioners (NP) and one nurse were the facilitators of the MCI. They all had experience of working in groups and with epilepsy patients.

\subsection{Data collection}

Table 3 presents an overview of the measurement instruments used for the process evaluation.

\subsubsection{Patients and relatives}

Patients and relatives filled in a short evaluation questionnaire after completion of the intervention. This questionnaire assessed: 1$)$ the perceived usefulness of the six meetings of the $\mathrm{MCI}$ and the eHealth tools on a 7-point Likert scale, ( $1=$ not at all useful-7 = very useful); 2 ) their opinion on seven statements about the purpose and content of the intervention ( $1=$ totally disagree- $7=$ totally agree $) ; 3$ ) an open question in which participants could express their ideas about the $\mathrm{MCI}$. The questionnaire was either given at the end of the booster session or sent by e-mail if a participant was not able to come to this last session.

All patients and their relatives, who attended at least one session, were invited to give their opinion during one of three group interviews, planned at two locations (Heeze and Maastricht). The interviews were conducted by one researcher (BW) and notes made by another (OG), neither involved in the intervention process. The topics discussed were: elements of the MCI (presence; usefulness); materials and working methods; opinion about facilitators; location, duration, frequency of $\mathrm{MCI}$; eligibility of the $\mathrm{MCI}$ for epilepsy patients and their relatives.

\subsubsection{Facilitators}

The facilitators kept a registration form and were invited to join a group interview. The registration form recorded attendance rate and violations of the intervention protocol (e.g. were any items not discussed? Reasons for not discussing these items). Additionally to this registration form the flipcharts from all sessions, were checked by the researcher (LL) to assess if all topics were discussed.

The group interview was a semi-structured interview, performed by one researcher (BW) and notes made by another (OG); neither had been involved in the intervention process. During this interview the facilitators were invited to evaluate the intervention. The topics dealt with were: training prior to the MCI; their role as a facilitator; recruitment of and eligibility of participants; perceived benefit to the participants; location, duration, frequency of $\mathrm{MCI}$, content of the $\mathrm{MCI}$ and material; and implementation tips.

\subsection{Data analysis}

All quantitative data gathered from evaluation questionnaires and registration forms were analysed with descriptive statistics using IBM SPSS statistics Version 2 for MacOs. Results from open-ended questions included in the evaluation questionnaire and group interviews were categorized, based on the content of the answers, by the main author (LL).

\subsection{Ethical consideration}

The study was approved by the Medical Ethics Committee of Maastricht University Medical Centre/Maastricht University. The study is registered in a public trial register (NTR4484). All participants gave informed consent. 
Measurements instruments and outcome measures for the process evaluation of the MCI.

\begin{tabular}{|c|c|c|c|c|}
\hline & $\begin{array}{l}\text { Evaluation questionnaire } \\
\text { participants }\end{array}$ & Registration forms & $\begin{array}{l}\text { Group interview } \\
\text { participants }\end{array}$ & $\begin{array}{l}\text { Group interview } \\
\text { facilitators }\end{array}$ \\
\hline \multicolumn{5}{|l|}{ Performance according to protocol } \\
\hline Were all components of the $\mathrm{MCI}$ delivered to participants? & $\mathrm{x}$ & $\mathrm{x}$ & & \\
\hline Were e-Health tools used? & & $\mathrm{x}$ & $\mathrm{x}$ & $\mathrm{x}$ \\
\hline Was a proactive action plan formulated? & & $\mathrm{x}$ & & \\
\hline \multicolumn{5}{|l|}{ Attendance and adherence } \\
\hline Attendance rate & & $\mathrm{x}$ & & \\
\hline Number of patients that dropped out of the intervention & & $\mathrm{x}$ & & \\
\hline Number, frequency and duration of the sessions & & $\mathrm{x}$ & $\mathrm{x}$ & $\mathrm{x}$ \\
\hline Recruitment & & & $\mathrm{x}$ & $\mathrm{x}$ \\
\hline \multicolumn{5}{|l|}{ Opinion on the intervention } \\
\hline Opinion participants & $\mathrm{x}$ & & $\mathrm{x}$ & \\
\hline Opinion relatives & $\mathrm{x}$ & & $\mathrm{x}$ & \\
\hline Opinion facilitators & & & $\mathrm{x}$ & $\mathrm{x}$ \\
\hline Barriers & $\mathrm{X}$ & $\mathrm{x}$ & $\mathrm{x}$ & $\mathrm{x}$ \\
\hline
\end{tabular}

\section{Results}

\subsection{Response}

Of the 52 patients who embarked on the $\mathrm{MCI}$, five patients, accompanied by three relatives, dropped out of the study. An additional two relatives withdrew from the MCI. The reasons for dropping out are addressed in Section 3.4 'Attendance and adherence'. The remaining 47 patients (90\%) and 32 relatives (86.5\%) received and returned the evaluation questionnaire. The group interviews were attended by 15 (28.8\%) patients and five (13.5\%) relatives. In total, 35 of the 52 patients replied to the request to attend a group interview. Seventeen patients replied that they could not attend any of the group interviews; five patients did not show up. The attendees of the group interviews represented eight of the 13 intervention groups. Five of the six facilitators attended the semi-structured group interview.

\subsection{Characteristics of the participants}

Twenty-eight of the 52 patients who started in the MCI-group were male (53.8\%), mean age of the patients was $40.5 \pm 13.5$ years (range 19-66 years). The majority of patients lived with a relative $(n=36$, $69.2 \%$ ) and were in employment or studying $(n=31,59.6 \%)$.

Of the 37 relatives, 16 were male (43.2\%). They were partners $(\mathrm{n}=$ $22,59.5 \%)$; parents ( $\mathrm{n}=13,35.1 \%)$; other family member $(\mathrm{n}=1,2.7 \%)$ and friends $(\mathrm{n}=1,2.7 \%)$.

The six facilitators were five female nurse practitioners, and one male nurse. All were nurses experienced in the field of epilepsy.

\subsection{Performance according to protocol (dose delivered)}

Thirteen groups were held at three locations in The Netherlands (Heeze, Nijmegen and Maastricht). Twelve groups were led by two facilitators; one group by one facilitator. The planned second facilitator could not be present. Every intervention group received the planned six sessions, which lasted for $2 \mathrm{~h}$ each. The mean group size for the 13 groups was 8.1 ( $\mathrm{SD}=1.3$; range $6-10)$. The mean group size for patients was $4.7(\mathrm{SD}=.5$; range $4-5)$ and the mean group size for relatives $3.4(\mathrm{SD}=1.2$; range $1-5)$.

A year after attending the two-day motivational interviewing course, four nurse practitioners started the $\mathrm{MCI}$. Four months later, for logistical reasons, two additional facilitators were needed, and so a nurse practitioner and an experienced nurse were added to the group. They had not attended the motivational interviewing course, which was not available at that time. All six facilitators received the two-hour explanation about the protocol and aim before embarking on their first MCI. The two additional facilitators were given extra training about the purpose of motivational interviewing and ways to perform this technique.

All 47 patients who participated in the $\mathrm{MCI}$, received the eHealth tool MEMS to assist them in self-monitoring. The Eppy eHealth tool could only be used in the first four groups because the application was removed from the appstores (i.e. Apple App Store and Google Play store) and was no longer available.

The participants in the group interviews (patients, relatives and facilitators) reported that all elements of the $\mathrm{MCI}$ were delivered according to protocol. One patient, however, stated that the items: risk-evaluation, self-monitoring and communication with health care providers, were only mentioned briefly, and that the focus was on the proactive action plan.

\subsection{Attendance and adherence}

Patients attended a mean number of 5.3 sessions (range 1 to 6 ). Five of the 52 patients withdrew from the MCI after 1 or 2 session(s). Reasons for discontinuing were: personal health problems $(n=2)$, $\mathrm{MCI}$ was not what they expected $(\mathrm{n}=2)$, and unknown $(\mathrm{n}=1)$.

Relatives attended a mean number of 5 sessions (range 1 to 6 ). Five of the 37 relatives who started the intervention stopped, reasons being: the patient stopped $(n=3)$, health problems $(n=1)$, and unknown $(\mathrm{n}=1)$.

Forty of the 47 patients who received the MEMS as an eHealth tool, reported using this after the $\mathrm{MCI}$ throughout the study; four patients stopped using the tool because: patients were used to their own system, and could not cope with another system $(n=2)$, stopped with medication $(\mathrm{n}=1)$, no longer interested in using the MEMS $(\mathrm{n}=1)$ and unknown $(\mathrm{n}=3)$; 15 patients wanted to continue using the MEMS after completion of the study.

Forty-six of the 47 patients and 30 of the 32 relatives who finished the $\mathrm{MCI}$, formulated a proactive action plan at the end of session five. Examples of such plans were: "taking my medication more regularly" or "improving my sleep time, by not playing on the computer till late at night" and "feeling less responsible for my child/partner with epilepsy". Participants described formulating a proactive action plan with the help of the five-step approach as useful but difficult. This was especially the case for the third step, in which future barriers and solutions for these barriers in establishing a goal, were explored. In the group interviews, most of the patients and relatives stated that they were still using elements of the MCI (e.g. risk evaluation; talking with a health care provider; using systems to remember medication intake; and using the framework for setting new goals). 


\subsection{Opinion about the intervention}

\subsubsection{Patients and relatives}

Table 4 shows that overall most patients and relatives had a favourable opinion about the MCI.

In the group interviews, participants, i.e. patients and relatives, reported that the number (6) and duration $(2 \mathrm{~h})$ of the sessions was good. Some participants, however, would have preferred to have a booster session after six to twelve weeks, instead of after three weeks.

Participants indicated the optimal group size to be 10 to 12 participants. The material (workbook, sheets) was considered to be sufficient, but perhaps the workbook could have been made available beforehand or be web-based.

According to the evaluation questionnaires, a majority of the participants perceived the sessions to be useful ( $>74 \%)$. The usefulness of eHealth tools was rated lower, especially by the patients (range 43\%-72\%) (for further details see Appendix 1). They stated in the group interviews that the MEMS could only be used for one kind of medication and that it was too fragile to be used by patients with seizures. After being dropped during a seizure, one of the patients' MEMS broke. Only a few of the patients of the group interview used 'Eppy', but they stated that it helped them with their self-monitoring activities; therefore, a similar eHealth tool should be made available.

In the group interviews, half of the participants reported that they had expected the $\mathrm{MCI}$ to be more of an educational programme, e.g. more education about specific topics such as how and when to use rescue medication; and types of seizures.

Important aspects of the $\mathrm{MCI}$ reported by most participants during the group interviews or on the evaluation questionnaires were: the participation of a relative (social support), and sharing ideas and feelings about having epilepsy with peers (peer support).

According to patients and relatives, no additional in- or exclusion criteria are needed for patients or relatives if they want to attend the $\mathrm{MCl}$. Also, in their opinion, there is no need to format more homogeneous groups, for instance based on age or educational level.

\subsubsection{Facilitators}

In their group interview, the facilitators reported that the number (6) and duration ( $2 \mathrm{~h}$ ) of the sessions was good and the group size should optimally be between 10 and 12 participants. In order to follow-up the action plan of the participants, facilitators preferred to have the booster session later, for instance after 3 months, or another kind of follow-up, such as a consultation with a nurse practitioner. All facilitators stated that being involved in the $\mathrm{MCI}$ required a considerable investment of time, because it was not embedded in their regular timetable. They also argued, however, that continuing with the $\mathrm{MCI}$ is a way of integrating self-management support into everyday practice, since it is part of their core competence framework [24]. The facilitators who followed the motivational interviewing course indicated that they would have preferred it closer to the start of the intervention. The two-hour training before and the support during the $\mathrm{MCI}$ were

\section{Table 4}

Participants' opinion of the $\mathrm{MCI}(\mathrm{n}=79) .{ }^{\mathrm{a}}$

\begin{tabular}{lll}
\hline Agreement on statements & $\begin{array}{l}\text { Patients } \\
\mathrm{n}(\%)\end{array}$ & $\begin{array}{l}\text { Relatives } \\
\mathrm{n}(\%)\end{array}$ \\
\hline Course is well organized & $42(89 \%)$ & $27(84 \%)$ \\
Purpose of the course is clear & $35(74 \%)$ & $23(72 \%)$ \\
The course was easy to understand & $41(87 \%)$ & $27(84 \%)$ \\
I have learned skills which help me in managing epilepsy & $35(74 \%)$ & $25(78 \%)$ \\
The link between the different parts of the course are clear & $38(81 \%)$ & $30(94 \%)$ \\
The eHealth-tools used, are of additional value in managing & $31(66 \%)$ & $22(69 \%)^{\mathrm{b}}$ \\
epilepsy & $39(83 \%)$ & $27(84 \%)$ \\
\hline I recommend this course to other people with epilepsy & 39
\end{tabular}

\footnotetext{
a Total number of patients $n=47$ and relatives $n=32$ that completed the MCI.
}

b Relatives responded often with NA. valued as useful and satisfactory. Support was especially useful on the subject of eHealth. The facilitators reported that explaining eHealth to the participants was not always easy, because they themselves sometimes experienced a lack of knowledge. In their opinion, the workbook for the participants should be simplified and their own protocol minimized.

\subsection{Barriers}

A major barrier was the fact that the eHealth application 'Eppy' could only be used in the first four groups. From group four on (December 2014) participants experienced problems downloading the application or using the app after updating their mobile devices, leading to the decision to discontinue its use. In 2015, the 'Eppy' was removed from the various stores.

Barriers mentioned by participants, which could influence recruitment were: the fact that some locations of the $\mathrm{MCI}$ were not within reach of public transportation, and the lack of information about the role of the relative in the intervention. One of the relatives stated: 'I thought I was only the chauffeur, didn't know I needed to work so hard, but it was well worth it'.

The main barrier mentioned by all facilitators was the fact that they could not follow-up the participants on their goal-setting tasks, and therefore could not support them further in self-management. They also mentioned that it was often not clear to the relatives that they should play an active role in the intervention.

\section{Discussion}

This process evaluation revealed that the $\mathrm{MCI}$ was largely performed according to protocol.

The overall attendance and adherence rates were high. The participants and the facilitators had a favourable opinion about the $\mathrm{MCI}$, and would recommend the intervention to other people with epilepsy and their relatives. Most patients used the MEMS as an eHealth tool; however, comments were made on the fact that it was not applicable for multiple medications. Some patients also indicated that they stopped, or didn't start using the MEMS, because it caused confusion with their regular method, such as a pill-minder. Almost every participant formulated at least one goal in their own proactive action plan.

Although most elements of the $\mathrm{MCI}$ were provided to the participants, there were some deviations from protocol: two facilitators did not receive the motivational interviewing course, one group had only one facilitator, and the 'Eppy', eHealth application, was no longer applicable for downloading for the last nine groups.

It is difficult to compare these results with other self-management interventions for people with epilepsy as process evaluations in this field are lacking [16]. When compared with the 'Plan Ahead 'intervention, a comparable self-management intervention for stroke patients and their partners [25], we find similarities and differences. Similarities, in addition to the high attendance rate, include the value patients and relatives placed on peer- and social support, especially in sharing and comparing ideas about how to deal with the consequences of having epilepsy or having a relative with epilepsy. A similar suggestion was to plan the booster session at a later time. Also, in both interventions, the facilitators reported the need to emphasize the active role of the relative, and the wish to receive their training closer to the start of the $\mathrm{MCI}$. The main difference with the 'Plan ahead' intervention was the fact that the proactive action plan in the $\mathrm{MCI}$ was executed according to protocol, and participants assessed this part of the $\mathrm{MCI}$ as being difficult, but useful.

The MCI aims to change behaviour of participants, but changing health behaviour is a process which acquires maintenance, since most of the intended behavioural changes tend to diminish after the active intervention phase $[26,27]$. How maintenance of health behaviour should be executed and by whom, requires further discussion [28]. Both 
participants and facilitators mentioned the need for a follow-up or maintenance plan. This could be realized by, for example, a booster session after 3 months instead of the 3 weeks we used in the MCI, or by a follow-up consultation by a nurse practitioner, who was involved in the $\mathrm{MCl}$ of these participants [28].

This study also has some limitations. First, the attendance rate for the participant group interviews was rather low, which may have led to bias in the results. Second, performance according to protocol was measured quantitatively (dose delivered) using registration forms administered by the facilitators. However, the quality (fidelity) of the performance of the facilitators was not assessed; this should be done by observation or video-recording, something we considered to be too intrusive for the participants [29]. Third, it is possible that participants and facilitators gave socially desirable answers. To limit this risk, all interviews were carried out by two independent interviewers, not involved in the $\mathrm{MCI}$, and the evaluation questionnaires, which were administered by the participants, were anonymous for the facilitators.

\section{Conclusion}

In conclusion, according to patients, relatives and facilitators, the $\mathrm{MCI}$ is feasible, although improvement is still possible. Suggested improvements are: planning the booster session at a later time, managing expectations about the MCI. Furthermore, eHealth and eHealth-tools should remain part of the intervention, although discussion and or further research is still needed to establish whether using MEMS is the best way to give patients insight in their medication intake pattern.
Based on this study, we recommend making some minor adjustments to the $\mathrm{MCI}$ and implementing the $\mathrm{MCI}$ in regular care when it proves to be (cost)-effective.

\section{Competing interests}

The authors declare that they have no competing interests.

\section{Funding}

This study was funded by the Netherlands Organization for Health Research and Development (ZonMw), grant application number 836011018. This study is registered with the Dutch Trial Register, part of the Dutch Cochrane Centre (NTR4484).

\section{Acknowledgement}

We would like to thank foundation and AARDEX Ltd. (Switzerland) for their contribution to the study, Drs O. Gershuni for her role during the group interviews and Mrs. Vollers for correcting grammatical and spelling errors. Furthermore, we would like to thank Dr. A. Pieron (UCB Pharma), Dr. L. Hageman (UCB Pharma), Drs. C. Caron (The Netherlands Epilepsy Foundation; Epilepsie Vereniging Nederland; EVN), M.K.H. van Kan-Sieswerda (EVN), Dr. R.H.C. Lazeron (Kempenhaeghe), Drs. A. Lenssen (CZ Health Insurance; Centraal Ziekenfonds), Drs. I.Y. Tan (Kempenhaeghe), Drs. C.I. Vader (Kempenhaeghe) and Dr. B. Vrijens (AARDEX Ltd.) for their role on our advisory board during the study.

\section{Appendix 1}

Number of participants that regarded elements of the MCI useful $(n=79){ }^{a}$

\begin{tabular}{|c|c|c|c|c|c|c|c|}
\hline \multirow[b]{2}{*}{$\mathrm{n}(\%)$} & \multicolumn{2}{|l|}{ Useful } & \multicolumn{2}{|c|}{ Nor useful/nor not useful } & \multicolumn{2}{|c|}{ Not useful } & \multirow[t]{2}{*}{ Overall missing ${ }^{\mathrm{b}}$} \\
\hline & Patients & Relatives & Patients & Relatives & Patient & Relatives & \\
\hline Session 1 & $35(74 \%)$ & $28(88 \%)$ & $7(15 \%)$ & $0(0 \%)$ & $3(6 \%)$ & $1(3 \%)$ & $5(6 \%)$ \\
\hline Session 2 & $39(83 \%)$ & 27 (84\%) & $4(9 \%)$ & $1(3 \%)$ & $4(9 \%)$ & $1(3 \%)$ & $3(4 \%)$ \\
\hline Session 3 & $37(78 \%)$ & $25(78 \%)$ & $4(9 \%)$ & $4(13 \%)$ & $5(11 \%)$ & $1(3 \%)$ & $3(4 \%)$ \\
\hline Session 4 & $40(85 \%)$ & $25(78 \%)$ & $4(9 \%)$ & $3(9 \%)$ & $3(6 \%)$ & $1(3 \%)$ & $3(4 \%)$ \\
\hline Session 5 & $36(77 \%)$ & $26(81 \%)$ & $3(6 \%)$ & $0(0 \%)$ & $3(6 \%)$ & $0(0 \%)$ & $11(14 \%)$ \\
\hline Booster session & $37(78 \%)$ & $26(81 \%)$ & $5(11 \%)$ & $2(6 \%)$ & $1(2 \%)$ & $0(0) \%$ & $8(10 \%)$ \\
\hline eHealth-tools: MEMS & $33(70 \%)$ & $23(72 \%)$ & $7(15 \%)$ & $2(6 \%)$ & $6(13 \%)$ & $3(9 \%)$ & $5(6 \%)$ \\
\hline eHealth-tools: ‘Eppy' & $20(43 \%)$ & $18(56 \%)$ & $6(13 \%)$ & $3(9 \%)$ & $12(26 \%)$ & $2(6 \%)$ & 18 (23\%) \\
\hline
\end{tabular}

Reasons for answering questions with NA were e.g. not attending sessions or using the eHealth-tools.

a Total number of patients $n=47$ and relatives $n=32$ that completed the $\mathrm{MCl}$.

$\mathrm{b}$ Total of missing is the combined number of missing values and questions answered with NA.

\section{References}

[1] Epilepsy fact sheet $N^{*} 999$. World Health Organisation; 2015.

[2] Jacoby A, Baker GA. Quality-of-life trajectories in epilepsy: a review of the literature. Epilepsy Behav 2008;12:557-71.

[3] Taylor RS, Sander JW, Taylor RJ, Baker GA. Predictors of health-related quality of life and costs in adults with epilepsy: a systematic review. Epilepsia 2011:52:2168-80.

[4] Kotsopoulos IAW, Evers SMAA, Ament AJHA, De Krom MCTFM. Estimating the costs of epilepsy: an international comparison of epilepsy cost studies. Epilepsia 2001;42: 634-40.

[5] Kotsopoulos IAW, Evers SMAA, Ament AJHA, Kessels FGH, de Krom MCTFM, Twellaar M, et al. The costs of epilepsy in three different populations of patients with epilepsy. Epilepsy Res 2003;54:131-40.

[6] Elwes RD, Marshall J, Beattie A, Newman PK. Epilepsy and employment. A community based survey in an area of high unemployment. J Neurol Neurosurg Psychiatry 1991;54:200-3.

[7] Pato Pato A, Cebrián Pérez E, Cimas Hernando I, Lorenzo González JR, Rodríguez Constenla I, Gude Sampedro F. Analysis of direct, indirect, and intangible costs of epilepsy. Neurología (English Edition) 2011;26:32-8.

[8] Ursum J, Rijken M, Heijmans M, Cardol M, Schellevis F. Zorg voor mensen met een chronische ziekte: organisatie van zorg, zelfmanagement, zelfredzaamheid en participatie. Overzichtstudies. Utrecht: NIVEL; 2011116.

[9] Raad voor de Volksgezondheid (RVZ). De participerende patiënt. Raad voor de Volgsgezondheid en Zorg; 2013.

[10] Barlow J, Wright C, Sheasby J, Turner A, Hainsworth J. Self-management approaches for people with chronic conditions: a review. Patient Educ Couns 2002;48:177-87.

[11] Bodenheimer T, Lorig K, Holman H, Grumbach K. Patient self-management of chronic disease in primary care. JAMA 2002;288:2469-75.
[12] Ouwens M, van der Burg S, Faber M, van der Weijden T. Shared decision making \& Zelfmanagement. Scientific Institute for Quality of Healthcare; 2012.

[13] Faber M, Harmsen M, van der Burg S, van der Weijden T. Gezamenlijke besluitvorming \& Zelfmanagement: Een literatuuronderzoek naar de effectiviteit ven en naar voorwaarden voor succes. Nijmegen: Scientifig Institute for Qoality of Healthcare (IQ healthcare); 2013.

[14] Haynes RB, Ackloo E, Sahota N, McDonald HP, Yao X. Interventions for enhancing medication adherence. Cochrane Database Syst Rev 2008:CD000011.

[15] Lemmens KM, Nieboer AP, van Schayck CP, Asin JD, Huijsman R. A model to evaluate quality and effectiveness of disease management. Qual Saf Health Care 2008;17: 447-53.

[16] Bradley PM, Lindsay B, Fleeman N. Care delivery and self management strategies for adults with epilepsy. Cochrane Database Syst Rev 2016;2 [CD006244].

[17] Aspinwall LG, Taylor SE. A stitch in time: self-regulation and proactive coping. Psychol Bull 1997;121:417-36.

[18] Tielemans NS, Schepers VP, Visser-Meily JM, van Erp J, Eijkenaar M, van Heugten CM. The Restore4Stroke self-management intervention 'Plan ahead!': rationale and description of the treatment protocol based on proactive action planning. Clin Rehabil 2014;28:530-40.

[19] Leenen LA, Wijnen BF, de Kinderen RJ, Majoie MH, van Heugten CM, Evers SM. (Cost)effectiveness of a multi-component intervention for adults with epilepsy: study protocol of a Dutch randomized controlled trial (ZMILE study). BMC Neurol 2014:14:255.

[20] Saunders RP, Evans MH, Joshi P. Developing a process-evaluation plan for assessing health promotion program implementation: a how-to guide. Health Promot Pract 2005;6:134-47.

[21] Thoolen B, Ridder DTDd, Bensing J, Gorter KJ, Rutten GEHM. Beyond good intentions: the development and evaluation of a proactive self-management course for patients recently diagnosed with type 2 diabetes. Health Educ Res 2008:23. 
[22] Miller WR, Rollnick S. Ten things that motivational interviewing is not. Behav Cogn Psychother 2009;37:129-40.

[23] Miller WR, Stephen R. Motivational interviewing: Preparing people for change. 3th ed. New York: Guilford Press; 2012.

[24] Fact sheet the nurse practitioner in the Netherlands; 2015.

[25] Tielemans NS, Schepers VP, Visser-Melly JM, van Haastregt JC, van Veen WJ, van Stralen HE, et al. Process evaluation of the Restore4stroke self-management intervention 'Plan Ahead!': a stroke-specific self-management intervention. Clin Rehabil 2016;30:1175-85
[26] Ryan P. Integrated theory of health behavior change. Clin Nurse Specialist 2009;23: 161-70.

[27] Ory MG, Smith ML, Mier N, Wernicke MM. The science of sustaining health behavio change: the health maintenance consortium. Am J Health Behav 2010;34:647-59.

[28] Hughes SL, Seymour RB, Campbell RT, Desai P, Huber G, Chang HJ. Fit and strong! bolstering maintenance of physical activity among older adults with lower-extremity osteoarthritis. Am J Health Behav 2010;34:750-63.

[29] Linnan L, Steckler A. Process evaluation for public health interventions and research an overview. Process evaluation for public health interventions and research; 2002. 